\title{
THE MEIOTIC BEHAVIOUR, FERTILITY AND STABILITY OF WHEAT-RYE CHROMOSOME ADDITION LINES
}

\author{
RALPH RILEY \\ Plant Breeding Institute, Cambridge
}

Received 27.ii.59

\section{INTRODUCTION}

THE chromosomes of rye, Secale cereale, a diploid, do not pair with those of common wheat, Triticum aestirum a hexaploid, in normal interspecific hybrids. Since, therefore, rye genes cannot be introduced into wheat chromosomes by meiotic recombination it has been suggested that characteristics of rye might be transferred to wheat by adding whole chromosomes of rye to the full complement of wheat. This can be accomplished by sequences of backcrosses and self-pollinations in the derivatives of wheat-rye hybrids or amphiploids (Florell, I93 I ; O'Mara, I940; Riley and Chapman, 1958). The most valuable derivatives of this process are disomic addition lines, which have a single pair of rye chromosomes added to the full complement of wheat, since they may be expected to be true-breeding and fertile because of their balanced chromosome number.

The purely genetical value of wheat-rye addition lines rests on the information they provide about the gene content of particular chromosomes isolated from the rest of the rye complement (Riley and Chapman, 1958). To be useful in plant breeding the rye chromosome must introduce genes which are epistatic to wheat genes or which interact with them.

However, the influence of the alien chromosome pair on fertility and meiotic regularity, and the constancy of the new chromosome status are of equal significance for the exploitation of addition lines in breeding. Moreover, since these characteristics illustrate the adequacy of the internal organisation of the genotype they present a measure of the degree to which the organisation is disrupted by the inclusion of an alien pair. Meiotic regularity, fertility and stability will, therefore, show what potential such lines would have in evolution and the extent to which the components of the genotype must be subjected to mutual adjustment for a balanced organisation to be acquired.

\section{MATERIALS AND METHODS}

The two species involved in the present work are Triticum aestivum $\mathrm{L}$. emend Thell, spp. vulgare MacKey variety Holdfast $(2 n=42)$ and Secale cereale L. strain. King II $(2 n=14)$.

The phenotypes and origins of lines with disomic additions of rye chromosomes I, II, III and IV have been described by Riley and Chapman (1958). One further line, which had the addition of a rye chromosome, designated $\mathrm{V}$, is discussed in 
the present paper. This chromosome has approximately equal arms, and plants in which it is disomic differ from the phenotype of Holdfast in having a very caespitose juvenile habit. At maturity chromosome $\mathrm{V}$ disomics are only two-thirds the height of Holdfast and have very short dense spikes.

The system of extracting the addition lines involved only one inbred wheat variety as a parent, so the wheat chromosomes must be highly homozygous. Since, also, all the addition material stcms from one hybrid plant from a wheat-rye cross, only one haploid sample of rye chromosomes is involved, so that the rye chromosomes which are disomic in the addition lines must also be homozygous, within the limits of mutation.

Meiosis was studied in orcein-Feulgen squashes of pollen mother cells from the anthers of greenhouse-grown plants. Three generations of disomic additions were sampled each in a separate season, only one generation of monosomic additions was examined. About 50 pollen mother cells per plant were scored.

In estimating the stability of the lines, the chromosome numbers of progenies were determined on squashes of root-tips pre-treated in mono-bromonaphthalene and stained by the Feulgen method. The freshly germinated grains, from which the root-tips were sampled, were from greenhouse-grown spikes which had been bagged to ensure self-pollination.

The fertility of disomic additions was estimated as the proportion of primary and secondary florets with grains. Florets were counted over the whole length of two spikes of each plant of a sample grown in the greenhouse. The spikes used had all been bagged to ensure self-pollination.

\section{OBSERVATIONS}

(i) Meiotic behaviour

First metaphase, on which the meiotic behaviour of the addition lines has been principally judged, provides a satisfactory numerical assessment of regularity. It is the earliest stage which can be easily examined in cereals and any major abnormality during this phase would be reflected in either the fertility of the parents or the genetic stability of the progeny. It offers, therefore, a key to the adequacy of the combined operation of the wheat and rye components of the lines.

In 43-chromosome monosomic additions, with a single rye chromosome transferred to the full wheat complement, 2 I bivalents and one univalent would normally be expected at meiosis. Similarly in 44chromosome disomic additions, with a balanced chromosome number - the rye chromosome being represented twice- -22 bivalents would be expected.

The recipient variety, Holdfast, usually had $2 \mathrm{I}$ bivalents at meiosis (table $\mathrm{I}$ ) but in 6 per cent. of pollen mother cells the formation of one or two bivalents had failed, leaving unpaired univalents. A frequency of cells with univalents of about this order is commonly found in $T$. aestivum but the frequency differs a good deal between varieties (Thompson and Robertson, I930; Hollingshead, I932; Person, 1956). The persistence of such irregularity in wheat must be related to the polyploid status of the species. This provides sufficient duplication in the genotype to ensure that the monosomic zygotes which result from the functioning of gametes, particularly embryo 
sacs, deficient for a chromosome are perfectly viable. The high fertility of monosomics in wheat (Sears, 1954) and the rapid return of their derivatives to the euploid condition must also temper the selection against univalent formation. For if, as Sears (1953) has demonstrated, a monosomic produces in its progeny a ratio of approximately one euploid : 3 monosomics, and assuming no differential selection, then 5 generations after the origin of a monosomic 75 per cent. of its descendants will again be euploid.

Hexaploid wheat will therefore tolerate a level of meiotic abnormality which would be a severe disadvantage in a diploid. Further evidence of this is provided by the single quadrivalents which were found very rarely in Holdfast pollen mother cells, as well as in cells of the addition lines. A similarly infrequent occurrence of quadrivalents, which are probably due to the conjugation of homoeologous (Huskins, I93 I ; Sears, I956) chromosomes from different genomes, has been noticed in other wheat varieties (Ellerton, I939; Love, I939; Huskins, I 94I).

The univalents found in wheat and also in the disomic addition lines may have resulted either from the failure of the chromosomes to pair at zygotene, asynapsis, or from paired chromosomes, separating at diplotene because chiasma formation had not occurred, desynapsis. In wheat, chromosomes which have paired at prophase without chiasma formation often remain in secondary, side-by-side, univalent associations until metaphase (Person, I955; Riley and Chapman, 1957). However, the univalents in the present material were rarely in side-by-side associations so that they were probably asynaptic rather than desynaptic in origin. This suggests disturbances of zygotene or pre-zygotene processes rather than interference with the timing or the intimacy of pachytene association, or with the control of chiasma formation.

The univalent frequency was greater than that of Holdfast in all the additions (table I). Cells with two univalents constituted the majority of those in which there was some pairing failure, but it was generally impossible to determine whether the univalents were rye or wheat chromosomes. The paired rye chromosomes could be recognised in occasional cells with univalents but in view of the frequency of univalents in wheat itself it is not surprising that such cells should occur. However, in most cells with two univalents it was probably the alien chromosomes which were unpaired since the frequency of cells with four univalents was rarely higher than that with two in Holdfast. Naturally in cells with four or more univalents there must have been unpaired wheat chromosomes but the data for none of the lines, except III, show any evidence of increased asynapsis of the wheat complement.

There were considerable differences between the addition lines in meiotic regularity (table I). Disomic additions of $I I$ and $V$ in which more than 90 per cent. of pollen mother cells were fully paired 
were almost as regular as Holdfast, despite the extra pair. Nor had they any cells with more univalents than Holdfast. Moreover these two chromosomes, with chromosome I, had the least effect on the conjugation of wheat chromosomes in monosomic additions (table 2). Apparently, therefore, these rye chromosomes cause little disturbance of the regulation of meiosis in wheat, and when disomic fit harmoniously into the pattern of wheat meiosis.

TABLE I

Meiotic chromosome pairing in disomic addition lines

\begin{tabular}{|c|c|c|c|c|c|c|}
\hline \multirow{2}{*}{ Line } & \multirow{2}{*}{ Plants } & \multirow{2}{*}{ Cells } & \multirow{2}{*}{$\begin{array}{l}\text { Proportion } \\
\text { with bivalents } \\
\text { only }\end{array}$} & \multicolumn{3}{|c|}{$\begin{array}{l}\text { Proportion of cells with various } \\
\text { no. of univalents }\end{array}$} \\
\hline & & & & 2 & 4 & 6 \\
\hline II & IO & $85^{\circ}$ & $0.9 \mathrm{I}$ & $0 \cdot 09$ & $\cdots$ & $\ldots$ \\
\hline III & 9 & 470 & 0.71 & $0.2 \mathrm{I}$ & 0.06 & $0.02 *$ \\
\hline IV & I 4 & 730 & 0.85 & 0.13 & O.OI & O.OI * \\
\hline V & 4 & 210 & 0.91 & 0.08 & O.OI & $\ldots$ \\
\hline Holdfast & 4 & 200 & 0.94 & 0.05 & O.OI & $\ldots$ \\
\hline
\end{tabular}

* There was one cell with ten univalents.

Monosomic additions of chromosomes III and IV showed a marked increase in the amount of asynapsis of wheat chromosomes compared with Holdfast, and it is evident that they carry genes which interfere with the pattern of wheat pairing. This is also apparent in the disomic additions in the extended range of univalents per cell, and the higher

TABLE 2

Meiotic chromosome pairing in monosomic additions

\begin{tabular}{|c|c|c|c|c|c|}
\hline \multirow{2}{*}{ Line } & \multirow{2}{*}{ Plants } & \multirow{2}{*}{ Cells } & \multicolumn{3}{|c|}{ Proportion of cells with various pairing } \\
\hline & & & $2 I^{\prime \prime} I^{\prime}$ & $20^{\prime \prime} 3^{\prime}$ & $19^{\prime \prime} 5^{\prime}$ \\
\hline $\begin{array}{c}\text { I } \\
\text { II } \\
\text { III } \\
\text { IV } \\
\text { V }\end{array}$ & $\begin{array}{l}3 \\
3 \\
3 \\
3 \\
3\end{array}$ & $\begin{array}{l}150 \\
150 \\
150 \\
150 \\
150\end{array}$ & $\begin{array}{l}0.90 \\
0.91 \\
0.83 \\
0.83 \\
0.96\end{array}$ & $\begin{array}{l}0 \cdot 09 \\
0 \cdot 09 \\
0 \cdot 16 \\
0 \cdot 15 \\
0 \cdot 04\end{array}$ & $\begin{array}{c}\text { O·OI } \\
\ldots \\
0 \cdot 0 I \\
0 \cdot 02 \\
\ldots\end{array}$ \\
\hline
\end{tabular}

frequency of cells with four univalents in the chromosome III material. There were much lower proportions of cells with complete pairing in both III and IV disomic additions, mainly due to the high frequency of cells with two univalents. The two univalents were probably rye chromosomes in most cells, so that chromosomes III and IV as well as causing more wheat asynapsis were also less likely to pair themselves than were II and V. 
There was no evidence of post-metaphase meiotic errors which could not be ascribed to the presence of univalents at first metaphase. Throughout sporogenesis, therefore, in some lines there were no greater irregularities than occurred in wheat, but in others there were persistent effects of the prophase asynapsis caused by disorganising interactions between the wheat and rye components.

(ii) Fertility

Estimates of fertility have been based on seed set because it measures the immediate efficiency of a line in terms of evolution and crop production. The number of grains set per spike was recorded, as well

TABLE 3

Fertility of disomic addition lines

\begin{tabular}{|c|c|c|c|}
\hline Line & Plants & $\begin{array}{c}\text { Fertility of } \\
\text { primary and } \\
\text { secondary florets }\end{array}$ & Grains per spike \\
\hline $\begin{array}{c}\text { II } \\
\text { III } \\
\text { IV } \\
\text { V } \\
\text { Holdfast }\end{array}$ & $\begin{array}{l}19 \\
18 \\
25 \\
10 \\
\text { 10 }\end{array}$ & $\begin{array}{l}0.50 \pm 0 . \mathrm{I} I \\
0.02 \pm 0.01 \\
0.74 \pm 0.02 \\
0.56 \pm 0.09 \\
0.91 \pm 0.02\end{array}$ & $\begin{array}{r}26 \cdot 1 \pm 2 \cdot 4 \\
5 \cdot 2 \pm 3 \cdot 5 \\
56 \cdot 9 \pm 2 \cdot 0 \\
29 \cdot 4 \pm 1 \cdot 9 \\
48 \cdot 0 \pm 1 \cdot 1\end{array}$ \\
\hline
\end{tabular}

as the proportions of primary and secondary florets fertile, so that an estimate of the total productivity of the line should be available.

It is clear that the fertility of all the lines examined was well below that of Holdfast (table 3). There were, moreover, very pronounced differences between the lines. Disomic additions of chromosome IV

TABLE 4

Fertility of monosomic additions

\begin{tabular}{|c|c|c|c|}
\hline Line & Plants & $\begin{array}{c}\text { Fertility of } \\
\text { primary and } \\
\text { secondary florets }\end{array}$ & Grains per spike \\
\hline $\begin{array}{c}\text { I } \\
\text { II } \\
\text { III } \\
\text { IV } \\
\text { V } \\
\text { Holdfast }\end{array}$ & $\begin{array}{r}\text { I I } \\
9 \\
6 \\
\text { I } 3 \\
9 \\
\text { IO }\end{array}$ & $\begin{array}{l}0.69 \pm 0.03 \\
0.64 \pm 0.05 \\
0.37 \pm 0.08 \\
0.59 \pm 0.04 \\
0.59 \pm 0.02 \\
0.91 \pm 0.02\end{array}$ & $\begin{array}{l}30 \cdot 5 \pm 3 \cdot 2 \\
42 \cdot 3 \pm 4 \cdot 7 \\
29 \cdot 0 \pm 6 \cdot 4 \\
39 \cdot 0 \pm 4 \cdot 7 \\
32 \cdot 0 \pm 3 \cdot 3 \\
4^{8 \cdot 0 \pm 1 \cdot 1}\end{array}$ \\
\hline
\end{tabular}

most nearly approached Holdfast, having 80 per cent. of its fertility, and because of much larger spikes, producing more grains per spike than the recipient variety. Under field conditions this would not give the IV addition line superior reproductive value because it has fewer spikes per plant and per unit area of ground. Whilst, on average, a 
spike of a IV disomic addition plant produces more grains than a Holdfast spike it is much less efficient having 26 per cent. compared with 9 per cent. of sterile florets.

The extremely low fertility of disomic additions of chromosome III was mainly due to the frequent failure of the anthers to dehisce because of a reduced proportion of apparently viable pollen grains. Only about 44 per cent. of the pollen of III disomics had contents which would take up aceto-carmine stain whereas the other lines and Holdfast had over 95 per cent. stainable pollen. The low fertility may be related to the meiotic irregularity of this line. However, most meiotic disturbances must have resulted in the production of euploid pollen with twenty-one wheat chromosomes and consequently of normal viability. If the low ferility of the line cannot be ascribed to meiotic irregularities then it must be due to the genetic effects of the chromosome, a conclusion which also accords with the low fertility of the monosomic addition lines.

It may be questioned whether the genetically conditioned infertility of chromosome III additions is related to the effects of the selfincompatibility alleles of rye. However, the association of infertility with poor pollen production and non-dehiscence of the anthers does not suggest the operation of an S allele. Moreover there is no evidence of the self-incompatibility mechanism of rye in wheat-rye amphidiploids in which the entire chromosome complements of the two species are combined, so it would be surprising to find any in single pair addition lines.

Thus the two lines involving chromosomes III and IV differed in having the highest and the lowest fertility amongst the lines considered but were similar in having the most irregular meiosis. This comparison strengthens the conclusion already drawn from the chromosome III additions, that reduced fertility was of genetic rather than cytological origin. Moreover, further support may be adduced from the observation that although disomic additions with chromosomes II and $\mathrm{V}$ were only slightly more irregular than Holdfast at meiosis yet they had little more than half its fertility. Indeed the low fertility of the addition lines is striking evidence of the impact of the deleterious interactions of rye and wheat genes.

\section{(iii) Stability}

As might have been expected from their meiotic behaviour, no addition line was completely stable; all produced a small proportion of progeny which deviated from the chromosome number of the parent (table 5). Most of the deviants were 43-chromosome monosomic additions which probably resulted from the functioning of gametes, deficient for the rye chromosome, which arose from meiotic divisions in which the rye chromosomes were unpaired. No 43-chromosome plant was recorded in which the rye chromosome remained disomic 
but a wheat chromosome was monosomic, although such plants could arise from cells with the rye chromosomes conjugated but with wheat univalents. Even assuming the random functioning of all classes of gametes 43-chromosome wheat monosomics would be very infrequent. However, the frequencies of plants deficient for a rye or for a wheat chromosome must have been affected by the relative competitive values of the two sorts of 2I-chromosome pollen compared with the usual 22-chromosome pollen. The pollen deficient for the rye chromosome, having returned to the euploid conditions, would compete vigorously with the 22-chromosome addition pollen and so would probably have a proportion of success in fertilisation in excess of its representation in the pollen population. By contrast it may be that pollen deficient for a wheat chromosome would have less success in fertilisation than 22-chromosome pollen and so wheat monosomics

TABLE 5

Chromosome numbers of the progeny of disomic additions

\begin{tabular}{|c|c|c|c|c|c|c|}
\hline \multirow{2}{*}{ Line } & \multirow{2}{*}{ Plants } & \multicolumn{5}{|c|}{ Proportion with various chromosome numbers } \\
\hline & & $4 \mathrm{I}$ & $4^{2}$ & 43 & 44 & 45 \\
\hline II & 64 & $\ldots$ & $\ldots$ & 0.06 & $0.9 \mathrm{I}$ & 0.03 \\
\hline III & 23 & 0.04 & $\ldots$ & 0.09 & 0.83 & 0.04 \\
\hline IV & $5 \mathrm{I}$ & $\ldots$ & $\ldots$ & 0.08 & 0.92 & $\ldots$ \\
\hline V & 61 & 0.01 & $\ldots$ & 0.18 & $0 \cdot 79$ & 0.02 \\
\hline
\end{tabular}

would be relatively under-represented in the progeny of a disomic addition.

Very rarely 45 -chromosome plants were found in the progenies of 44-chromosome disomic addition parents. These probably resulted from the functioning of 23-chromosome gametes which arose when both partners of an asynaptic pair were incorporated in the same gamete.

There was no relationship between the stability and the fertility of the lines, but stability reflected meiotic regularity, although imperfectly. The line involving chromosome III, which was the most irregular at meiosis was not unstable to the same extent, and whilst the $\mathrm{V}$ line had the most regular meiosis, it was the least stable.

Monosomic addition plants segregated an excess of 42 -chromosome progeny (table 6). Indeed the occurrence of about 75 per cent. without the unpaired chromosome, and of about 25 per cent. with it, is consistent with the segregation of monosomic chromosomes in wheat (Sears, I953; Morrison, 1953). This pattern of segregation in wheat arises from the transmission of the unpaired chromosome to about one-quarter of all gametes but the almost exclusive success in fertilisation of euploid pollen. By analogy, therefore, if the rye chromosomes 
were included in about a quarter of the embryo sacs, 22-chromosome pollen can rarely be successful, except in the chromosome III line.

The instability observed would lead to a rapid decay of the alien disomic component of a population which was originally entirely disomic. The shift of such a population to the euploid state would be exaggerated by the excess of euploids in the progeny of 43 -chromosome monosomic additions (table 6) which would quickly be established in the population. Thus, with a fresh increment of monosomic additions from disomic additions each generation, the return of most of the derivatives of monosomic additions to the euploid status and the stability of the euploids, there would be a continual run down to the euploid level and no return. Consequently, a character introduced with a rye chromosome would have to possess enormous selective

TABLE 6

Chromosome numbers of the progeny of monosomic additions

\begin{tabular}{|c|c|c|c|c|c|c|}
\hline \multirow{2}{*}{ Line } & \multirow{2}{*}{ Plants } & \multicolumn{5}{|c|}{ Proportion with various chromosome numbers } \\
\hline & & $4 I$ & $4^{2}$ & 43 & 44 & 45 \\
\hline I & 219 & O.OI & $0 \cdot 77$ & $0 \cdot 20$ & $0 \cdot 02$ & $\ldots$ \\
\hline II & 47 & $0 \cdot 03$ & $0 \cdot 70$ & $0 \cdot 2 \mathrm{I}$ & 0.06 & $\ldots$ \\
\hline III & I 15 & $\ldots$ & $0 \cdot 60$ & $0 \cdot 25$ & $0 \cdot 14$ & o.or \\
\hline IV & 56 & $\ldots$ & $0 \cdot 71$ & 0.25 & $0 \cdot 04$ & $\ldots$ \\
\hline V & $5^{8}$ & 0.02 & 0.59 & $0 \cdot 34$ & 0.03 & $0 \cdot 02$ \\
\hline
\end{tabular}

value in evolution or agriculture to outweigh its elimination from the population by the loss of the alien chromosome.

\section{DISCUSSION}

The meiotic behaviour, fertility and stability of the present addition lines were generally consistent with what has previously been observed in similar material. Florell (r93r), whilst observing that the alien chromosomes tended either to precede the wheat chromosomes or to lag behind them at first anaphase, thought, from the cytological evidence, that constant wheat-like strains with a rye chromosome could be produced. O'Mara's (1953) conclusions, based principally on the study of rye chromosomes I, were closer to those that may be drawn from the present work, "Since the rye chromosome often occurs in the univalent condition, even when it is present as two homologues, stable additions of the rye chromosome to wheat would seem to be improbable". However, the line with which O'Mara (r95I) dealt was less regular at meiosis and less stable than any line studied in the present work.

The meiotic behaviour of O'Mara's addition of chromosome I was similar to that of the present addition of chromosome II to Holdfast 
when it was first extracted as a disomic (Chapman and Riley, 1955). The high level of 90 per cent. asynapsis which was originally observed in this line has never been repeated since (table $\mathrm{I}$ ), and there is no clear explanation for the different behaviour of subsequent generations derived from this plant.

Hyde (I953) had no complaint about the meiotic regularity of addition lines with pairs of chromosomes of Haynaldia villosa transferred to wheat, except for chromosome IV which caused asynapsis of the wheat chromosomes as well as being asynaptic itself. In the disomic addition line with the chromosome of Agilops umbellulata responsible for leaf-rust resistance added to wheat, Sears (1956) found a higher frequency of cells with full bivalent formation, but a lower stability amongst the progeny, than occurs in most additions with rye chromosomes. Matsumura (1952) added single chromosomes of the D genome of the hexaploid species Triticum spelta to the full complement of the tetraploid $T$. polonicum, and in a line with a pair of $D$ genome chromosomes, "D diplosomic", there was some reversion to the euploid condition, indicating meiotic irregularity.

In alien addition lines in which pairs of chromosomes of Nicotiana glutinosa were added to the full complement of $\mathcal{N}$. tabacum there was apparently about Io per cent. of pollen mother cells in which a bivalent failed (Gerstel, 1945). This is a degree of irregularity essentially similar to that in alien chromosome additions based on wheat. It may be concluded, therefore, that no alien addition line has been produced which equals the recipient species in the efficiency of its reproductive processes.

Through the action of natural selection for high reproductive values and for restricted genetic variation the genotypes of most successful species are adjusted to condition regular meiotic division and high fertility. Part of the adjustment involves the integration of the components of the genotype so that they are mutually coordinated to function together harmoniously to produce the optimum expression of the selected character. It is not, therefore, surprising that the added rye chromosomes should often have failed to fit neatly into the operation of the wheat genotype, for there had been no opportunity for selection to balance the contributions of two species, long isolated and presumably widely divergent in genetic structure.

The disturbance of the meiotic behaviour of the wheat chromosomes was very slight, except in additions with chromosome III, indicating considerable genetic stability of the control of meiosis in wheat. By contrast, in some additions, the rye chromosomes were often unpaired, failing in some way to match the wheat division. These chromosomes were not entirely susceptible to the wheat control of division and had no internal regulation which was effective in the wheat background.

The instability of the lines was a symptom of their meiotic irregularity and it is through stability and fertility that selection for meiotic 
regularity would normally operate. However, there was no correlation between meiotic behaviour and fertility. The generally low fertility must be accepted as a further example of the deleterious interactions of rye genes with the wheat genotype (Riley and Chapman, 1958). Indeed the failure of the two genetic components of the lines to work together is particularly evident in this character. If, therefore, alien addition material were to have a successful evolutionary future, heterozygosity would be necessary to provide the genetic variation on which selection could operate to produce a new balance within the genotype. By the system of extraction the rye addition lines examined in this study must be almost completely homozygous, but Riley (1956) has described how heterozygosity could be introduced into the rye chromosomes alone, leaving the agriculturally satisfactory wheat genotype intact.

The meiotic irregularity and instability of alien additions would be exaggerated on a population scale by the rapidity of the return to the euploid condition due to the high competitive ability of euploid pollen over addition pollen (O’Mara, I95I; Hyde, I953; Sears, 1956; Moav, 1958). The only exception, with euploid pollen at a disadvantage, concerns the $K l$ chromosome of $\mathcal{N}$ icotiana plumbaginifolia which when added, as a monosomic, to $\mathcal{N}$. tabacum has a lethal effect on euploid pollen, so that only addition pollen is viable (Cameron and Moav, I956). Normally, however, the poor competitive ability of addition pollen, symptomatic of genetic unbalance, causes a vast excess of euploids in the progenies of monosomic additions, which are usually the first products of meiotic irregularity in disomic additions. Disregarding any differential reproductive capacity, which would hasten the process, the decay of the addition fraction of a population which was originally entirely disomic would be so rapid as to give alien additions little value in agriculture, even if the reduced fertility were acceptable because of other benefits. In a natural population it is apparent that severe selective elimination of euploids would be necessary for the alien addition status to be stabilised.

Consequently, as the alien chromosome pair cannot be satisfactorily added to the full complement of the recipient species, its introduction is more likely to be successful if it replaces one of the chromosome pairs of the recipient species, to form an alien chromosome substitution line. Such lines can be extracted in the derivatives of crosses between alien addition lines and monosomics of the recipient species. The substitution of rye chromosome pairs for wheat pairs has been described by Kattermann (1938), O’Mara (1947) and Riley and Bell (1959), and the replacement of a $\mathcal{N}$. tabacum pair by a $\mathcal{N}$. glutinosa pair by Gerstel ( 1943 ). The advantage of substitution lines should lie in their improved stability compared with additions. For any pollen deficient for the alien chromosomes, as a result of asynapsis of the alien pair, will also be deficient relative to the euploid condition. It will therefore compete less well with substitution pollen than euploid 
pollen would compete with addition pollen, following a similar elimination of the alien chromosome in addition lines.

Substitution lines may, thus, minimise the effects on stability of the lack of genetic integration between the alien chromosome pair and the recipient genotype. However, some of the genetical activity of the alien pair may still fit poorly into the overall operation of the recipient genotype, although it may be that some substitutions will produce better genetical balance than others. Presumably some chromosome pairs will match genetically and will take over each other's functions efficiently, so that they will compensate more adequately than others for the deficiency in the recipient complement. It may, therefore, be necessary to test an alien chromosome pair, to be substituted, against each pair of the recipient species. As O'Mara (I953) has pointed out, 147 different substitutions of rye chromosomes for wheat chromosomes are possible. However, studies of the capacity of chromosomes to compensate for one another will test the basic similarities of diverse genetic material. Moreover, the lines developed will permit further examination of the internal organisation of the genotype and may have practical value in crop improvement.

\section{SUMMARY}

I. Lines with single pairs of rye chromosomes added to the full complement of wheat chromosomes were less regular at meiosis than wheat, principally because of the failure of the rye chromosomes to pair.

2. This led to the loss of the rye chromosome from some of the progeny of disomic additions, and would cause the rapid return of an addition population to the euploid state.

3. No addition line was as fertile as the recipient wheat variety, although there were big differences between lines with different rye chromosomes in fertility as well as in meiotic regularity. This is taken to imply lack of genetic balance between the wheat and rye components of the lines.

Acknowledgments.-Gratitude is due to $\mathrm{Mr}$ Victor Chapman who has helped in many aspects of this work, and to Mrs K. M. Pauley, Mr H. A. Torrens and Mr T. E. Miller who have given technical assistance at various times.

\section{REFERENCES}

CAMERON, D. R., AND MOAv, R. 1956. Inheritance in Nicotiana tabacum. XXVII. Pollen killer, an alien genetic locus inducing abortion of microspores not carrying it. Genetics, 42, 326-335.

CHAPMAN, v., AND RILEY, R. I955. The disomic addition of rye chromosome II to wheat. Nature, Lond., I75, Iogr.

ELlerton, S. 1939. The origin and geographical distribution of Triticum sphaerococcum Perc. and its cytogenetical behaviour in crosses with $T$. vulgare Vill. 7. Genet., 38, 307-324. 
FLORELL, V. H. I93I. A cytologic study of wheat $\times$ rye hybrids and backcrosses. 7. Agric. Res., 42, 34I-362.

GERSTEL, D. U. I943. Inheritance in Nicotiana tabacum. XVII. Cytogenetical analysis of glutinosa-type resistance to mosaic disease. Genetics, 28, 533-536.

GERSTEL, D. U. 1945. Inheritance in Nicotiana tabacum. XX. The addition of $\mathcal{N}$ icotiana glutinosa chromosomes to tobacco. F. Hered., 36, 197-206.

HollingsheAD, L. I932. The occurrence of unpaired chromosomes in hybrids between varieties of Triticum vulgare. Cytologia, 3, I I9-I4I.

Huskins, C. L. r93r. A cytological study of Vilmorin's unfixable dwarf wheat. 7. Genet., 25, I I 3-I 24 .

Huskins, C. L. I94I. Polyploidy and mutations. Amer. Nat., 75, 329-344.

HYDE, B. B. I953. Addition of individual Haynaldia villosa chromosomes to hexaploid wheat. Amer. 7. Bot., 40, I 74-182.

KattermanN, G. I938. Über konstante halmbehaarte Stamme aus Weizenroggenbastardierung mit $2 n \times 42$ Chromosomen. Zeits. Ind. Abst. Ver., 74, 354-375.

Love, R. M. I939. The role of cytology in wheat improvement. Proc. 7 th Int. Cong. Genet. Edin., p. I97.

Matsumura, s. I952. Chromosome analysis of the Dinkel genome in the offspring of a pentaploid wheat hybrid. III. 29-chromosome D-haplosomics and their relations to nullisomics. Cytologia, I7, 35-49.

MOAV, R. I958. Inheritance in Nicotiana tabacum. XXIX. The relationship of residual chromosome homology to interspecific gene transfer. Amer. Nat., 92, $267-278$.

morrison, J. w. I953. Chromosome behaviour in wheat monosomics. Heredity, $7,203-2 I 7$.

o'mara, J. G. I940. Cytogenetic studies on Triticale. I. A method for determining the effects of individual Secale chromosomes on Triticum. Genetics, 25, 40 I-408.

o'mara, J. G. I947. The substitution of a specific Secale cereale chromosome for a specific Triticum vulgare chromosome. Genetics, 32, 99-100.

o'mARA, J. G. I95I. Cytogenetic studies on Triticale. II. The kinds of intergeneric chromosome addition. Cytologia, I6, 225-232.

o'maRA, J. G. I953. The cytogenetics of Triticale. Bot. Rev., 19, 587-605.

PERSON, C. I955- An analytical study of chromosome behaviour in a wheat haploid. Canad. 7. Bot., 33, I I-30.

PERSON, C. 1956. Some aspects of monosomic wheat breeding. Canad. F. Bot., $34,60-70$.

RILEY, R. I956. Adding individual rye chromosomes to wheat. Wheat Information Service, 4, I 2-I3.

RILEY, R., AND BELL, G. D. H. 1959. The evaluation of synthetic species. Proceedings First Int. Wheat Genetics Symposium. (In press.)

RILey, R., AND chapman, v. I957. Haploids and polyhaploids in Aegilops and Triticum. Heredity, II, I95-207.

RILEY, R., AND GHAPMAN, V. I958. The production and phenotypes of wheat-rye chromosome addition lines. Heredity, I2, 30I-3 I 5 .

SEARS, E. R. 1953. Nullisomic analysis in common wheat. Amer. Nat., 87, 245-252.

SEARS, E. R. I954. The aneuploids of common wheat. Res. Bull. Mo. Agric. Sta., no. 472 .

SEARS, E. R. I956. The transfer of leaf-rust resistance from Aegilops umbellulata to wheat. Brookhaven Symposia in Biology, 9, I-22.

THOMPson, w., AND ROBERTSON, H. T. I930. Cytological irregularities in hybrids between species of wheat with the same chromosome number. Cytologia, I, $252-262$. 